\title{
Addison's Disease Presenting with Cerebral Edema
}

\author{
Caroline Geenen, Ingrid Tein, Robert M. Ehrlich
}

\begin{abstract}
Background: Increased intracranial pressure with encephalopathy has rarely been reported in Addison's disease. Method: Case Study. Results: A 16-year-old female who presented with cerebral edema of unknown etiology was eventually diagnosed as having Addison's disease. She had early morning headaches, fatiguability, diarrhea and deterioration in school performance. She was hyponatremic with a serum sodium of $128 \mathrm{mmol} / \mathrm{L}$ and hyperkalemic with a serum potassium of $5.9 \mathrm{mmol} / \mathrm{L}$. She had a low serum osmolality (264 mosm), high urine osmolality (533 mosm) and high urine sodium (87 mosm). She had a postural drop in blood pressure and diffuse hyperpigmentation. An ACTH stimulation test revealed a low baseline cortisol and no response to ACTH. Plasma renin activity was increased. Serum ACTH was elevated. She responded well to intravenous fluids and solu-cortef and was discharged on hydrocortisone and florinef. She remains well 18 months after the acute episode with no neurologic complaints or findings. Conclusion: Addison's Disease should be considered in the differential diagnosis of symptomatic cerebral edema and idiopathic intracranial hypertension.
\end{abstract}

RÉSUMÉ: Oedème cérébral comme mode de présentation de la maladie d'Addison. Introduction: Une augmentation de la pression intracrânienne avec encéphalopathie a rarement été rapportée dans la maladie d'Addison. Méthode: Études de cas. Résultats: Il s'agit d'une jeune femme de 16 ans qui présentait un oedème cérébral d'étiologie unconnue au moment de la consultation initiale et chez qui nous avons éventuellement posé un diagnostic de maladie d'Addison. L'histoire a révélé la présence de céphalées matinales de fatigabilité et de diarrhée et de détérioration du rendement scolaire. Nous avons découvert une hyponatrémie chez cette jeune fille avec un sodium sérique à $128 \mathrm{mmol} / \mathrm{L}$ et une hyperkaliémie avec un potassium sérique à $5.9 \mathrm{mmol} / \mathrm{L}$. Elle avait une osmolalité sérique faible (264 mosm), une osmolalité urinaire élevée (533 mosm) et un taux élevé de sodium urinaire $(87 \mathrm{mosm})$. Elle présentait un abaissement postural de la tension artérielle et une hyperpigmentation diffuse. Un test de stimulation à l'ACTH a révélé un taux basal de cortisol bas et aucune réponse à l'ACTH. L'activité de la rénine plasmatique était augmentée. L'ACTH sérique était élevée à 178 (normale $<22$ $\mathrm{pmol} / \mathrm{L}$ ). Elle a bien répondu à l'hydratation intraveineuse avec solu-cortef. Elle est retournée à domicile sous hydrocortisone et florinef. Elle se porte toujours bien 18 mois après l'épisode aigu, sans symptômes neurologiques. Conclusions: Ce cas illustre l'importance de considérer la maladie d'Addison dans le diagnostic différentiel de l'oedème cérébral symptomatique ainsi que dans celui de l'hypertension intracrânienne idiopathique.

Can. J. Neurol. Sci. 1996; 23: 141-145

Neurologic presentations of Addison's Disease can include either encephalopathy, or, a syndrome similar to idiopathic intracranial hypertension with papilloedema, raised intracranial pressure, and no abnormal findings on neuroimaging or neurological examination. Increased intracranial pressure with encephalopathy has only rarely been reported. The following is a case report of a young female who presented with symptomatic cerebral edema of unknown cause who was eventually diagnosed as having Addison's Disease.

\section{CASE Report}

A 16-year-old white female presented to a peripheral hospital with increasing headaches, drowsiness and vomiting over a 10 day period.

\footnotetext{
Divisions of Neurology (C.G., I.T.) and Endocrinology (R.M.E.), The Hospital for Sick Children, Toronto

RECEIVED SEPTEMBER 27, 1994. ACCEPTED IN FINAL FORM JAUARY 18. 1996.

Reprint requests to: Dr. Ingrid Tein, Division of Neurology, The Hospital for Sick Children, 555 University Avenue, Toronto, Ontario, Canada M5G 1X8
} 
On arrival she was found to be disoriented with a stiff neck and had a temperature of 38.8 Celsius. Lumbar puncture revealed normal cytologic, protein $(0.27 \mathrm{~g} / \mathrm{L})$ and glucose $(3.3 \mathrm{mmol} / \mathrm{L})$ profiles. She was transferred to our institution because of fluctuating level of consciousness and continued headache, with a provisional diagnosis of encephalitis.

Sixteen months prior to admission, she had begun to develop headaches which occurred in the early morning and were not associated with nausea or vomiting. On one occasion they had migrainous features with scintillating scotomata. They were easily treated with acetaminophen. A CT scan of the head done at that time was normal. Twelve months prior to admission she began to feel fatigue in the late afternoon and suffered bouts of intermittent crampy diarrhea once weekly. Six months prior to admission her school performance had begun to deteriorate and her " $\mathrm{A}$ " grades fell to just passing grades

Perinatal and developmental history were entirely unremarkable. There was a family history of migraine in the maternal uncle and grandmother. She had one sibling who was well and both parents were alive and well. There was no family history of neurologic disease and no known consanguinity.

On arrival at The Hospital for Sick Children she was oriented in three dimensions but intermittently drowsy. Vital signs were stable with a blood pressure of $95 / 65 \mathrm{~mm} \mathrm{Hg}$. She was afebrile. Her disc margins were sharp and there were no focal neurological findings. Initial blood work including $\mathrm{CBC}$, electrolytes, renal function, liver function, and ammonia were normal except for a serum sodium of $127 \mathrm{mmol} / \mathrm{L}$. A serum glucose was $5.8 \mathrm{mmol} / \mathrm{L}$ and serum osmolality was $257 \mathrm{mmol} / \mathrm{kg}$ which quickly corrected. A urine drug screen was negative. Urine ketones were elevated on admission ranging from 7.8-15.6 mmol/L. She was initially treated with acyclovir and cloxacillin intravenously.

The patient rapidly deteriorated and on the following day a CT scan of the head revealed diffuse cerebral edema with small ventricles (Figure). She was noted on examination to have papilloedema. A ventriculostomy of the right frontal horn was performed and CSF pressure was $35 \mathrm{~mm} \mathrm{Hg}$. Following hyperventilation and mannitol diuresis, a CT scan revealed improvement of the cerebral edema. A cerebral angiogram was normal and did not reveal any venous sinus thrombosis. Repeat examination of the CSF from the ventriculostomy site revealed a normal profile.

On day 8 she was extubated and the ventricular catheter was removed. She was alert and able to answer questions and obey commands. There were no focal neurologic findings. The following day she developed significant bradycardia, hypotension and apnea requiring car-

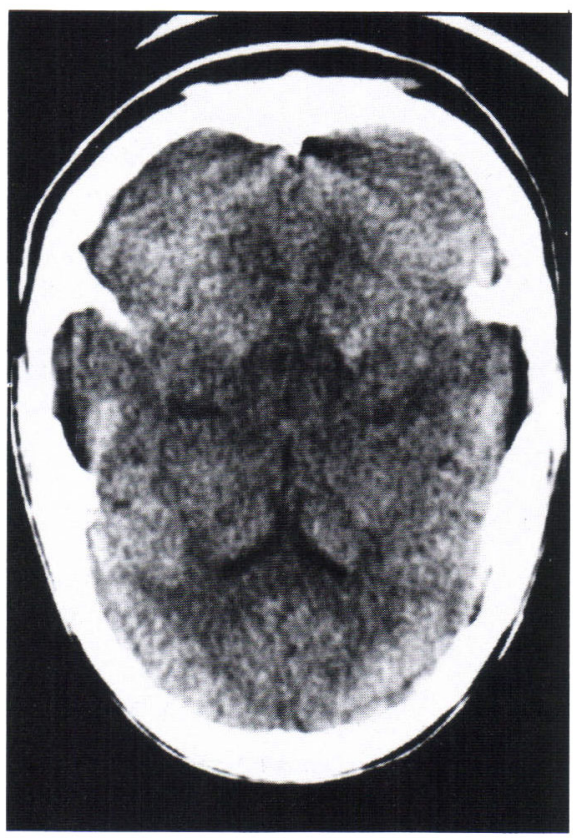

Figure: CT scan of the head revealed diffuse cerebral edema with effacement of the basal cisterns. diopulmonary resuscitation. An urgent $\mathrm{CT}$ of the head revealed recurrence of severe cerebral edema. A ventriculostomy catheter was reinserted, and hyperventilation and diuresis were re-instituted. At no time during this illness did she receive corticosteroids. The CSF profile remained unremarkable and the cultures were negative. Bacteremia, coagulopathy and liver dysfunction ensued. On day 13 she remained unresponsive and an EEG revealed spindle coma with focal attenuation in the right parietoccipital region. The following day she became awake and alert and had no focal neurologic signs. ICP readings revealed pressures of $15 \mathrm{~mm} \mathrm{Hg}$ with spontaneous increases to $40 \mathrm{~mm} \mathrm{Hg}$. On day 16 while undergoing an MRI scan of the brain, her blood pressure became barely palpable but responded to volume resuscitation and inotropic support. The MRI brain was normal.

On day 18 she was awake and able to obey commands and communicate with the staff. There were no focal neurologic findings or deficits but the bilateral papilloedema persisted. She was extubated and 2 days later was transferred to a medical ward.

Other investigations during the course of illness included normal serum lactate and serum quantitative amino acid determinations. Total and free serum carnitine were normal. Urine organic acids revealed large amounts of ketones. Serum lead was normal. Serum free RBC porphyrin was 3.17 (normal < 1.33), which was felt to be a non-specific acute phase reactant. ANA was positive at $1: 640$ with a speckled pattern and chromosome negative. VDRL was negative. Complement fixing antibodies to HSV, enterovirus, mycoplasma and influenza $A$ and $B$ were normal. Latex agglutination CMV antibody titres were normal. Antibody titres to eastern and western equine virus, St. Louis virus, California virus and Powassan virus were all less than 1:10. Antibody titres to measles were greater than 1:64, to mumps greater than $1: 8$, and to rubella were $1: 20$. An HIV test was negative. A right frontal brain biopsy of cortical gray matter was entirely normal. There were no nuclear or cytoplasmic inclusions and there was no evidence of perivascular inflammation or micronodular formation. Electronmicroscopy revealed no viral particles and no mitochondrial abnormalities. PCR for $\mathrm{EBV}, \mathrm{CMV}$, and herpes virus were negative.

On arrival to the ward she was found to be hyponatremic with a serum sodium of $128 \mathrm{mmol} / \mathrm{L}$ and hyperkalemic with a serum potassium of $5.9 \mathrm{mmol} / \mathrm{L}$. Serum chloride was $88 \mathrm{mmol} / \mathrm{L}$ and serum glucose was $5.9 \mathrm{mmol} / \mathrm{L}$. She had a low serum osmolality $(264 \mathrm{mosm})$, high urine osmolality ( $533 \mathrm{mosm})$ and high urine sodium $(87 \mathrm{mosm})$. Blood pressure fell from $100 / 60 \mathrm{~mm} \mathrm{Hg}$ lying to $90 / 50 \mathrm{~mm} \mathrm{Hg}$ upon sitting, with presyncope. For the first time, she was noted to have diffuse hyperpigmentation. An ACTH stimulation test revealed a low baseline cortisol $(146 \mathrm{nmol} / \mathrm{L})$ and no response to $\mathrm{ACTH}$, with a 60 minute cortisol of $134 \mathrm{nmol} / \mathrm{L}$, and 90 minute cortisol of $131 \mathrm{nmol} / \mathrm{L}$. Plasma renin activity was increased at 4.92 (normal $<0.56 \mathrm{ng} / \mathrm{L} / \mathrm{s}$ ). Serum ACTH was elevated at 178 (normal $<22 \mathrm{pmol} / \mathrm{L}$ ). Abdominal ultrasound was normal. Adrenal, ovarian, and thyroid antibodies were negative.

She responded very well to intravenous fluids and Solu-Cortef 27.5 $\mathrm{mg}$ intravenously every 4 hours. She was discharged home on day 28 on hydrocortisone $10 \mathrm{mg}$ TID and florinef $0.1 \mathrm{mg}$ BID. She has now been seen in follow-up for 18 months and remains well with no headaches or neurologic complaints, and has an entirely normal neurologic examination. She is once again an " $\mathrm{A}$ " student.

Other investigations done after discharge included visual and auditory brainstem evoked potentials which were normal. Somatosensory evoked potentials were mildly abnormal with normal central conductions but asymmetrical amplitude of cortical responses. Very long chain fatty acids were normal, consistent with normal peroxisomal function. Repeat determinations of serum lactate, total and free carnitine and quantitative amino acids and urine amino acids, and organic acids were all normal.

\section{Discussion}

The occurrence of encephalopathy and papilloedema in Addison's Disease was last reviewed by Jefferson in $1956 .{ }^{1} \mathrm{He}$ described one patient with Addison's Disease and papilloedema who at autopsy demonstrated cerebral edema, as well as two other cases of gross cerebral edema (autopsy proven) in patients 
with adrenal insufficiency. He noted that two previous similar case reports had been published in $1950^{2}$ and $1952 .^{3}$ Both of these patients also had papilloedema; cerebral edema was confirmed at autopsy in one, and the other patient had regression of the papilloedema with steroid treatment.

Jefferson's review of the records at the Radcliffe Infirmary, Oxford, revealed a further 3 cases of autopsy proven cerebral edema in patients in whom a clinical or post-mortem diagnosis of Addison's Disease was made.

Previous to the 1950's, several other reports exist $t^{4-8}$ describing encephalopathic patients with adrenal insufficiency who were found to have cerebral edema at autopsy. Unfortunately however, clinical information is scanty in certain of these cases so that a direct relationship cannot be assumed.

Since 1956, only one case of papilloedema in a patient with Addison's Disease has been reported. ${ }^{9}$ These authors described a 42-year-old male with a long history of symptoms of adrenal insufficiency in the setting of exposure to tuberculosis. He presented with "A disordered state of consciousness, anisocoria, papilloedema, horizontal nystagmus, rigidity and neck stiffness". A diagnosis of "pseudotumor cerebri" during an adrenal crisis was made, although the report does not give results of CSF pressure or imaging investigations (angiography). The patient was described as improving neurologically after initiation of steroid therapy, but a reassessment of his papilloedema was not reported.

The etiology of papilloedema and raised intracranial pressure in Addison's Disease is not clear. The effect of adrenal insufficiency on water and electrolyte distribution in the brain was studied by Baethmann and Van Harreveld ${ }^{10}$ in rats. They found that after adrenal insufficiency was induced by adrenalectomy, water, sodium and potassium content of the brain accumulated over both the extra- and intracellular compartments resulting in an increase in volume of both the extracellular space and cellular elements of the brain. They hypothesized that this was the result of either a failure of a metabolic mechanism or that there was disordered transport of electrolytes across the blood-brain barrier in which energy-dependent processes are also involved.

It is unknown how the severity, or perhaps the duration of adrenal insufficiency affects the production of intracranial hypertension. It is also unclear whether papilloedema alone is on a continuum with the more severe state of symptomatic cerebral edema, or whether two distinct pathologies and etiologies exist.

Hyponatremia itself is known to cause encephalopathy. Plum and Posner ${ }^{11}$ note that most patients with slowly developing or only moderately severe hyponatremia are often confused or delirious and may have asterixis or myoclonus. Coma can occur in the late phase of water intoxication and is more common with acute rather than chronic hyponatremia. Coma or convulsions usually occur in the setting of serum sodium values between 95 to $110 \mathrm{meq} / \mathrm{L}$.

Hyponatremic encephalopathy has been shown to be associated pathologically with brain swelling and increased intracranial pressure leading to decreased cerebral blood flow. ${ }^{12-14}$ These changes are not related to treatment of hyponatremia, as such brain damage often occurs in untreated patients.

The pathology of the brain in Addison's Disease has not been studied in the English modern literature, aside from the case reports described above. Jefferson ${ }^{1}$ noted that in Thomas Addison's original paper "On the Constitutional and Local
Effects of Disease of the Supra-Renal Capsules", eleven patients came to necropsy and four had brain examination. One brain was normal, two had cerebral atrophy, and one was described as having "grey matter of a very deep colour". The available foreign literature ${ }^{15}$ is not further revealing secondary to neuropathological variables and incomplete descriptions of the clinical courses of the patients studied.

Our patient presented with symptoms of raised intracranial pressure, likely long-standing. In the context of fever, confusion, and neck stiffness, however, an infectious etiology was sought as the cause. In retrospect, the parents agreed that she had looked more tanned over the preceding few months, but hyperpigmentation was not noted until her arrival to the general ward. The presence of hyperpigmentation may have been missed in the I.C.U. setting because of low lighting. The disturbance of electrolytes was also not noted until her arrival to the ward except for the low serum sodium on admission. The cause of Addison's Disease in our patient is as yet unknown. We have not been able to demonstrate evidence of auto-immune disease, hemorrhage, granulomatous disease or adrenoleukodystrophy. ${ }^{16.17}$ Her cerebral edema responded to traditional methods of treatment (hyperventilation and mannitol), and recurred when these measures were stopped. She did not receive steroids until the diagnosis of Addison's Disease was made, and the cerebral edema did not recur once treatment was instituted.

Our case illustrates the need to consider Addison's Disease in the differential diagnosis of symptomatic cerebral edema, as well as in those patients with idiopathic benign intracranial hypertension.

\section{ACKNOWLEDGEMENT}

I.T. is a recipient of a Medical Research Council of Canada Scholarship.

\section{REFERENCES}

1. Jefferson A. Clinical correlation between encephalopathy and papilloedema in Addison's disease. J Neurol Neurosurg Psychiatry 1956; 19: 21-27.

2. Boudin G, Funck-Brentano J, Gayno M. Maladie d'Addison par aplasie sur rénale et syndrome para-biermérien. Bull et Mém Soc Méd Hop Paris 1950; 66: 1736-1741.

3. Walsh FB. Papilledema associated with increased intracranial pressure in Addison's disease. Arch Ophthamol Chicago 1952; 47: 86.

4. Klippel M. Encéphalopathie Addisonnienne. Communication III. Rev Neurol (Paris) 1899; 7: 898-899.

5. Lebrun R. Contribution a l'etude de l'encephalopathie Addisonnienne. These, Paris 1937.

6. Gosset AEM. L'encephalopathie Addisonnienne. These, Bordeaux 1941

7. Wells HG. Addison's disease with selective destruction of suprarenal cortex ("suprarenal cortex atrophy"). Arch Pathol Chicago 1930; 10: 499-523.

8. Duffin JD. Cortical necrosis of adrenal glands associated with Addison's disease: report of 8 cases. Arch Pathol Chicago 1943; 35: 649-666.

9. Eisner M, Dobrohorska H, Spychalska-Szymanska T, Stachowski A. Objawy rzekomego guza mózgu w przelomie nadnerczowym w przebiegu choroby Addisona. (Polish) ("Addison's disease with manifestations of pseudotumor cerebri during adrenal crisis). Pol Tyg Lek 1976; 31: 585-586.

10. Baethmann A, Van Harreveld A. Effect of adrenal insufficiency on water and electrolyte distribution in the brain. J Neuropathol Exp Neurol 1973; 32: 394-407. 
11. Plum F, Posner JB. eds. Multifocal, diffuse and metabolic brain disease causing stupor or coma. In: The Diagnosis of Stupor and Coma. Philadelphia: F.A. Davis Co., 1982; 177-303.

12. Arieff AI. Hyponatremia, convulsions, respiratory arrest and permanent brain damage after elective surgery in healthy women. $\mathrm{N}$ Engl J Med 1986; 314: 1529-1535.

13. Fraser CL, Arieff AI. Fatal central diabetes mellitus and insipidus resulting from untreated hyponatremia; a new syndrome. Ann Intern Med 1990; 112: 113-119.

14. Arieff AI, Ayus JC, Fraser CL. Hyponatremia and death or permanent brain damage in healthy children. Br Med J 1992; 304: 1218-1222.
15. Prados SM. Lesiones cerebrales en la enfermedad de Addison. (Spanish). (Cerebral lesions in Addison's disease). Arch Neurobiol (Madr) 1969; 32: 475-488.

16. Moser HW, Moser AE, Singh I, O'Neill BP. Adrenoleukodystrophy: survey of 303 cases: biochemistry, diagnosis, and therapy. Ann Neurol 1984; 16: 628-641.

17. Heffungs W, Hameister $\mathrm{H}$, Ropers $\mathrm{HH}$. Addison disease and cerebral sclerosis in an apparently heterozygous girl: evidence for inactivation of the adrenoleukodystrophy locus. Clin Genet 1980; 18: 184-188. 